\title{
Chirurgiczne leczenie kamicy ślinianki podżuchwowej - opis przypadku
}

\author{
Surgical treatment of submandibular gland lithiasis - case report
}

Katedra i Klinika Chirurgii Stomatologicznej i Periodontologii, Uniwersytet Medyczny im. Karola Marcinkowskiego w Poznaniu Chair and Department of Dental Surgery and Periodontology, Poznan University of Medical Sciences, Poland

DOI: http://dx.doi.org/10.20883/df.2021.9

STRESZCZENIE

Sialolithiasis dotyczy dużych gruczołów ślinowych, najczęściej ślinianki podżuchwowej. Autorzy przedstawiają przypadek 58. letniego pacjenta, u którego zdiagnozowano, na podstawie CBCT, dużych rozmiarów sialolity w obrębie przewodu ślinianki podżuchwowej. Chorego zakwalifikowano do zabiegu chirurgicznego zewnątrzustnego. Badanie kliniczne i ocena radiologiczna potwierdziły rozpoznanie kamicy ślinianki podżuchwowej.

Słowa kluczowe: kamica, ślinianka podżuchwowa, leczenie chirurgiczne.

\section{ABSTRACT}

Sialolithiasis is associated with large salivary glands, most commonly the submandibular gland.

The authors present the case of a 58-year-old patient who was diagnosed based on CBCT with large sialoliths in the submandibular gland duct. The patient was qualified for extraoral surgery. Clinical examination and radiological evaluation confirmed the diagnosis of submandibular gland stones.

Keywords: Sialolithiasis, submandibular salivary gland, surgical treatment.

\section{Wstęp}

Struktury anatomiczne wypełnione płynem, takie jak pęcherzyk żółciowy, moczowody czy przewody gruczołowe, mają predyspozycje do powstawania złogów mineralnych na skutek zaburzenia homeostazy substancji mineralnych i ilości płynu w przewodach.

Kamica ślinianki jest najczęstszym schorzeniem gruczołów ślinowych. Niektóre źródła określają częstość jej występowania na około 1,2\% [1], bardziej współczesne podają występowanie objawowej kamicy z częstością 0,45\% przebadanej populacji [2]. Średni wiek chorych z kamicą wynosi 40,5 roku dla ślinianki podżuchwowej, 47,8 roku dla ślinianki przyusznej i 50 lat w przypadku małych gruczołów ślinowych [3]. Kamica najczęściej manifestuje się w śliniance podżuchwowej - 87\%, następnie w śliniance przyusznej - 10\% i w śliniance podjęzykowej 3\%. Wśród badań obrazowych, w rozpoznawaniu zmian patologicznych przewodów ślinowych, najczęściej wykorzystuje się ultrasonografię i sialografię. Zastosowanie ultrasonografii wysokiej rozdzielczości pozwala na wykrycie złogów wielkości 1-2 mm w około 90\% przypadków [4].
Częstsze umiejscowienie się kamieni w obrębie ślinianki podżuchwowej lub jej przewodzie jest efektem składu śliny produkowanej w gruczole, posiadającej więcej wapnia i fosforanów niż ślina ślinianki przyusznej. Wykazuje ona również znaczną lepkość [5].

Istnieje kilka teorii powstawania sialolitów. Jedna z nich zakłada zaburzenie wydzielania z jednoczesnym wytrącaniem się składników śliny na skutek procesów zapalnych w śliniance. Kolejna teoria uważa zmiany w obrębie cząsteczek organicznych za strukturę matrycową dla kryształów wapnia. Jeszcze inna teoria wyjaśnia powstawanie kamienia jako zaburzenia metaboliczne spowodowane przez zasadowość wodorowęglanu i wytrącanie wapnia przez fosforany [6].

Tyler i Boynton [7] podają odwodnienie i przyjmowane leki za istotny czynnik tworzenia się sialolitów w efekcie zmniejszenia wydzielania śliny i wzrostu jej lepkości [8].

Ryzyko kamicy rośnie zatem w przypadku chorób zmieniających skład śliny, przy reakcjach zapalnych w obrębie samego gruczołu i w jego regionie oraz zaburzeniach metabolicznych, takich jak hiperkalcemia i cukrzyca. Przewlekłe zapalenie 
ślinianki, zespół Sjorgena i zwiększenie stężenia wapnia we krwi wpływają znacząco na powstawanie kamieni [9].

Czynnikiem predysponującym do rozwoju kamicy jest zastój śliny. Fizjologicznie może występować w przypadku anomalii przewodów wyprowadzających, takich jak zwężenia, rozdwojenia lub zagięcia [10].

Obturacja przewodu ślinowego przez kamień prowadzi do powstania obrzęku gruczołu i bakteryjnego zakażenia miąższu ślinianki, który potęguje dolegliwości bólowe podczas spożywania pokarmów. Najczęstszymi izolowanymi patogenami z objętych zapaleneniem ślinianek są Staphylococcus aureus lub Streptococcus viridans. Efektem zamknięcia przewodu wyprowadzającego jest ból kolkowy i obrzęk ślinianki [11, 12].

Długotrwała blokada przewodu wyprowadzającego może doprowadzić do zaniku gruczołu, co wiąże się z zaburzeniami jego funkcji wydzielniczej i ostatecznie zwłóknienia narządu [13].

Oprócz anomalii anatomicznych kamicy sprzyjają nieprawidłowości w składzie śliny związane ze wzrostem stężenia wapnia, zwiększeniem gęstości czy zaburzeniami pH w przebiegu chorób infekcyjnych jamy ustnej [14].

Kamienie ślinowe mogą osiągać rozmiary od kilku milimetrów do kilku centymetrów. W swoim składzie najczęściej posiadają węglan wapnia, fosforany z węglanami w postaci hydroksyapatytu, minimalną ilość magnezu, potasu i amoniaku, równomiernie rozmieszczone w złogu. Zawierają również substancje organiczne, jak polisacharydy, glikoproteiny czy nekrotyczne pozostałości komórkowe, jednak składniki nieorganiczne zdecydowanie przeważają nad organicznymi [15].

W diagnostyce klinicznej istotne jest, że kamienie w obrębie ślinianek pojawiają się jednostronnie, nie powodując kserostomii. Małe gruczoły ślinowe błony śluzowej jamy ustnej warg, gardła, krtani, policzków, podniebienia skutecznie zastępują niewydolne duże ślinianki. Pierwszym objawem kamicy jest zatem obrzęk i ból, niekiedy w przypadku zmian przewlekłych odczucie słonego smaku. Diagnostyka obrazowa obejmuje badanie ultrasonograficzne, sialografię, rezonans magnetyczny, tomografię komputerową i sialoendoskopię [16]. Ostatnia metoda jest również metodą zabiegową pozwalającą na rozszerzenie przewodu wyprowadzającego i ewentualne wprowadzenie stentu.

\section{Opis przypadku}

Bezobjawowy pacjent lat 58 z prawostronnym obrzękiem w okolicy podżuchwowej został zdiagnozowany za pomocą tomografii komputerowej (ryciny 1, 2). Uwidocznione złogi, ze względu na rozmiar, uniemożliwiły wybór zachowawczych metod leczniczych oraz metod małoinwazyjnych. Po uzyskaniu zgody pacjenta zdecydowano się na usunięcie złogów bez usuwania gruczołu z dojścia zewnątrzustnego. Zabieg wykonano w znieczuleniu miejscowym w osłonie antybiotykowej. Po usunięciu złogów ranę zaopatrzono szwem ciągłym. Przebieg zabiegu ilustrują ryciny 3-5.

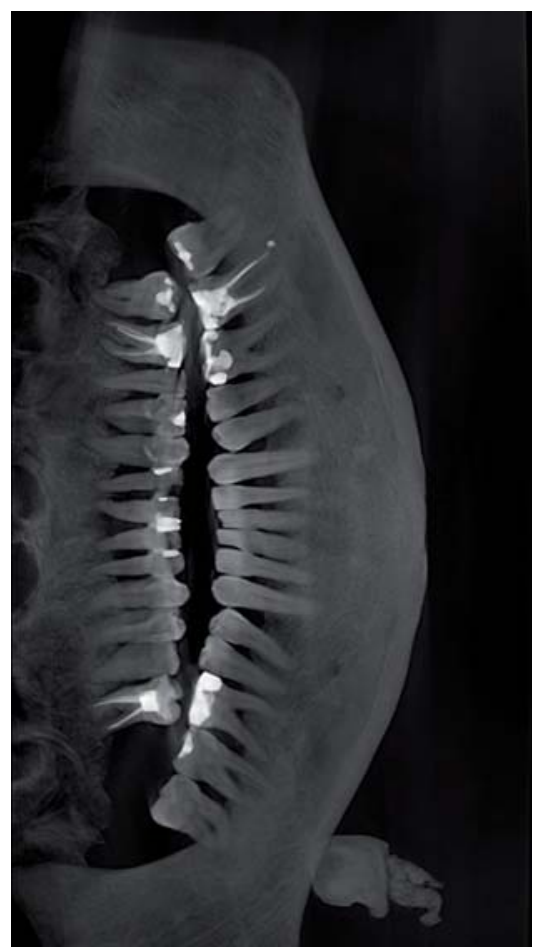

Rycina 1. Pantomogram

Figure 1. Panoramic photo

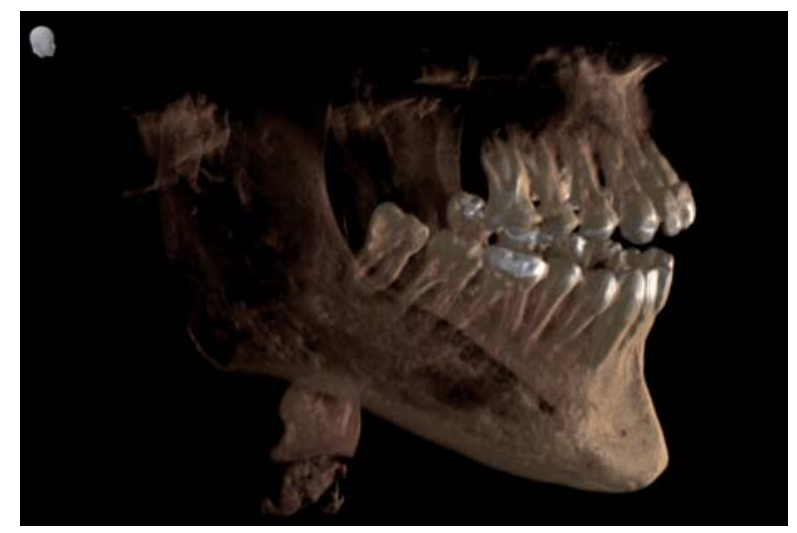

Rycina 2. Tomografia komputerowa Figure 2. Computed tomography 


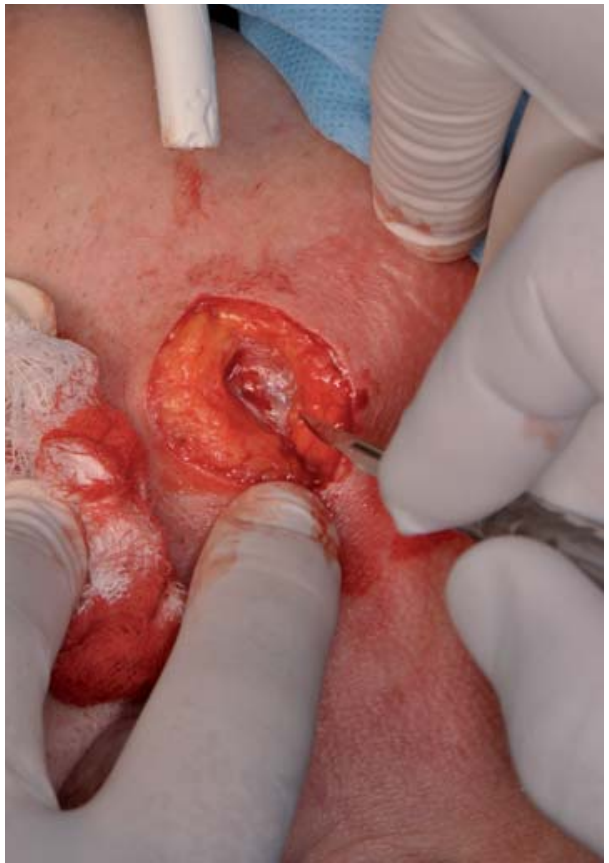

Rycina 3. Nacięcie skóry

Figure 3. Skin incision

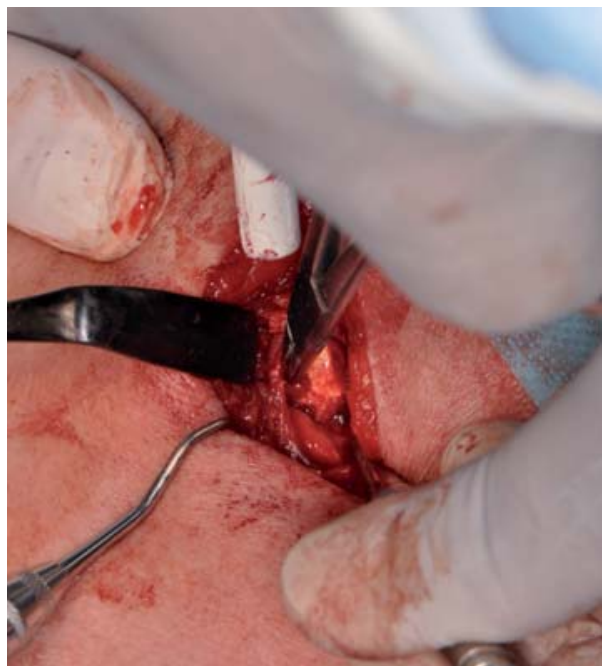

Rycina 4. Wyłuszczenie kamienia

Figure 4. Glandstones extraction

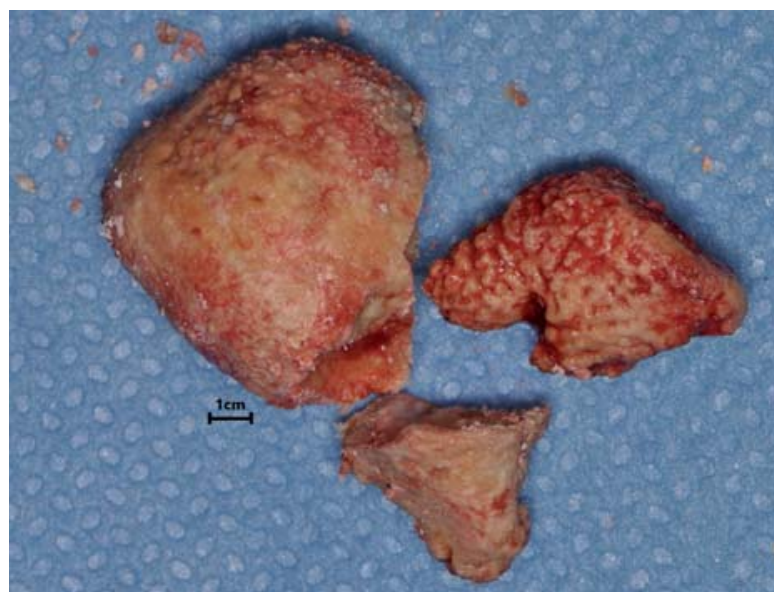

Rycina 5. Obraz kamieni usuniętych ze ślinianki w skali $1 \mathrm{~cm}$ Figure 5. Glandstones in scale of $1 \mathrm{~cm}$

\section{Dyskusja}

Ślinianka podżuchwowa (glandula submandibularis) położona jest poniżej dolnego brzegu żuchwy. Ze względu na specyficzny skład śliny częściej tworzą się w niej kamienie zatykające przewód wyprowadzający i prowadzące do przewlekłego stanu zapalnego. Umiejscowienie kamienia i jego wielkość decydują o wyborze metody leczniczej.

W przypadku kamieni mniejszych niż $5 \mathrm{~mm}$ metodą z wyboru powinna być małoinwazyjna sialoendoskopia, umożliwiająca usunięcie złogu w warunkach ambulatoryjnych, w warunkach umożliwiających szybką funkcjonalną regenerację tkanki gruczołowej. W sytuacji, kiedy kamień jest wyczuwalny na dnie jamy ustnej w przewodzie wyprowadzającym, dopuszczalne jest nacięcie przewodu nad kamieniem i usunięcie go w znieczuleniu miejscowym [17].

Drage i Brown [18] opisują techniki rozszerzania balonowego zwężeń przewodu ślinowego dające pozytywne klinicznie i radiologicznie wyniki.

Do zabiegów nisko inwazyjnych zaliczyć można również fragmentację kamienia przy pomocy ultradźwięków. McGurk opisuje leczenie kamicy ślinianki podżuchwowej przy pomocy pozaustrojowej litotrypsji falą uderzeniową (ESWL) [19]. Metoda ma wysoki odsetek skuteczności.

Niestety w przypadkach dużych kamieni i nawracających niedrożności, a tym samym powtarzających się infekcji, metodą $z$ wyboru jest usunięcie ślinianki podżuchwowej $w$ całości. Zabieg wykonywany jest w znieczuleniu ogólnym w warunkach szpitalnych. Cięcie prowadzone jest wzdłuż fałdu skórnego $2 \mathrm{~cm}$ poniżej dolnego brzegu żuchwy. Po wypreparowaniu ślinianki należy zabezpieczyć przewód gruczołowy. Obszar pooperacyjny zabezpiecza się poprzez założenie drenu Redona na 2 dni celem zapobiegania gromadzenia się śliny i krwi w ranie. Zabieg ten niesie jednak za sobą ryzyko uszkodzenia przebiegających w sąsiedztwie gałęzi nerwu twarzowego i nerwu podjęzykowego [20].

Coraz częściej wykonuje się zabiegi łączone wykorzystujące sialoendoskopię i metody chirurgiczne.

W opisanym przypadku zdecydowano się na usunięcie złogów bez usuwania gruczołu. Pacjent od 7 miesięcy pozostaje pod obserwacją kliniczną. Nie zaobserwowano nawrotów stanu zapalnego.

\section{Oświadczenia}

Oświadczenie dotyczące konfliktu interesów Autorzy deklarują brak konfliktu interesów w autorstwie oraz publikacji pracy.

\section{Źródła finansowania}

Autorzy deklarują brak źródeł finansowania. 


\section{Piśmiennictwo}

[1] Rice DH. Noninflammatory, non-neplastic disorders of the salivary glands. Otolaryngol Clin North Am. 1999;32:835-43.

[2] Escudier MP, McGurk M. Symptomatic sialoadenitis and sialolithiasis in the English population, an estimate of the cost of hospital treatment. Br Dent J. 2001;186(9):463-6.

[3] Escudier M. Epidemiology and aetiology of salivary calculi. In: McGurk M, Renehan A, editors. Controversies in the management of salivary gland disease.Oxford and new York: Oxford University Press; 2001.p.249-55.

[4] Iro H, Zenk J, Koch M. Modern concepts for the diagnosis and therapy of sialolithiasis. HNO 2010;58(3):218-24.

[5] Iro H, Zenk J. Konzepte fur Diagnostik und Therapie des Seichelsteinleidens. In Deutsches Arzteblatt. 2003;100(9):556.

[6] Blatt JM. Studies in sialolithiasis: Concepts for diagnosis and therapy of salivary stone disease. South Med J. 1964;57:723-729.

[7] Tyler T, Boynton, Stuart E, Lieblich. Oral radiol unsual case of a sialolith: a case report. Oral Surg. Oral Med Oral Pathol. 2014;117(1):9-10.

[8] Houh KC, Eisele DW. Ethnologie factor in sialolithiasis. Otolaryngol Head Neck Surg. 2011;145:935-939.

[9] Lustmann J, Regev E, Melamed Y. Sialolithiasis. A survey on 245 patients and review of the literature. Int J Oral Maxillofac Sure. 1990;19:135-8.

[10] Nahlieli O, Bar T, Shacham R, Eliav E, Hecht-Nakar L. Managment of chronic recurrent parotitis: current therapy. J Oral Maxillofac Sure. 2004;62:1150-5.

[11] Alyas F, Lewis K, Willians M et-al. Diseases of the submandibular gland as demonstrated using high resolution ultrasound. Br J Radiol. 2005;78(928):362-9.

[12] Capps EF, Kinsella JJ, Gupta M, et-al. Emergency imaging assessment of acute, montraumatic conditions of the head and neck. Radiographics. 2010;30(5): 1335-52.
[13] Williams MF. Sialolithiasis. Otolaryngologic Clinics of North America. 1999;32:819-834.

[14] Kraaje S, Karagozoglu KH, Forouzanfar T, Veeman EC, Brand HS. Salivary stones: symptoms, aetiology, biochemical composition and treatment. Br Dent J. 2014;217:E23.

[15] Sproll C, Naujoks. Entzündungen und obstruktive Speicheldrüsenerkrankungen. In:MKG-Chirurg. 2015;8:128-141.

[16] Kalinowski M, Heverhagen JT, Rehberg E, Klose KJ, Wagner HJ. Comparative study of MR sialography and digital subtraction sialography for benign salivary gland disorders. AJNR. 2002;23:1485-1492.

[17] Mc Gurk M, Makolissi J, Brown JE. Intra-oral removal of stones from the hilum of the submandibular gland: report of technique and morbidity. Int J Oral Maxillofac Surg. 2004;33:683-6.

[18] Drage N, Brown J, Escudier MP, Wilson RF, Mc Gurk M. Balloon dilatation of salivary duct strictures: report on 36 treated glands. Cardiovasc Intervent Radiol. 2002;25(5):356-9.

[19] Mc Gurk M, Escudier MP, Brown JE. Modern managment of salivary calculi. Br J Sure. 2005;92:107-12.

[20] Kuttner H. Uber entzündliche Tumoren der Submandibular-Speicheldrüse. Brunst Bier Klin Chir. 1896;15: 815-834.

Zaakceptowano do edycji: 28.06.21 Zaakceptowano do publikacji: 29.09.21

Adres do korespondencji:

Elżbieta Smolak

Katedra i Klinika Chirurgii Stomatologicznej

i Periodontologii UMP

ul. Bukowska 70

60-812 Poznań 